\title{
EVALUASI PENGENDALIAN INTERNAL TERHADAP KREDIT DIRAGUKAN PADA PT. BANK SULUTGO DI MINAHASA INDUK
}

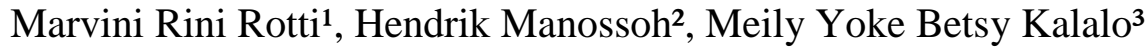 \\ ${ }^{1,2,3}$ Fakultas Ekonomi dan Bisnis, Jurusan Akuntansi. Universitas Sam Ratulangi, J1. Kampus Bahu Manado, \\ 95115, Indonesia
}

E-mail :marvinirotti.mr@gmail.com

\begin{abstract}
Credit is the most important operational activity in bank operations, where credit has the greatest asset value. Despite the risk of losses generated market business so it takes internal control to maintain corporate property and with bad loans. Good handling of credit through the company's internal control allows for doubtful loan to smooth again. The purpose of this research is to evaluation the internal control of doubtful loan on PT. Bank SulutGo in Minahasa and whether matching with the principles of COSO. This research method is qualitative method. The technique of data collection are interview and documentation. The processing and analysis of data are done by using qualitative data and descriptive analysis. Based result the company's management has applied the basic concept and the principle of internal control based of COSO (Committee of Sponsoring Organizations).
\end{abstract}

Keywords: Internal control, doubtfull loan.

\section{PENDAHULUAN}

Perbankan memiliki peran yang sangat penting terhadap pergerakan roda perekonomian Indonesia, karena memberikan pelayanan di bidang perkreditan. Usaha perbankan sebagaimana diketahui bukanlah badan usaha biasa seperti halnya perusahaan yang bergerak di bidang perdagangan dan jasa, melainkan suatu badan usaha yang bergerak di bidang jasa keuangan. Bank mempunyai kegiatan usaha khusus yakni menghimpun dana dari masyarakat dalam bentuk simpanan dan menyalurkan dana kepada masyarakat yang membutuhkan dalam bentuk kredit. Kondisi dimana kredit yang telah disalurkan kepada masyrakat ternyata tidak dibayar kembali oleh pihak debitur tepat pada waktunya sesuai dengan perjanjian sebelumnya yang terdiri dari pokok beserta bunganya digolongkan menjadi non performing Loan (NPL) atau kredit bermasalah. Untuk menghindari dan meminimalisir kredit bermasalah maka perlu adanya control yang baik dari perusahaan terhadap prosedur pemberian fasilitas kredit. Kontrol yang dimaksud adalah Struktur Pengendalian Internal. Pengendalian Internal (Internal Control) adalah suatu proses yang dilaksanakan oleh dewan direksi, manajemen dan personel lainnya dalam suatu entitas, yang dirancang untuk menyediakan keyakinan yang memadai berkenaan dengan pencapaian tujuan perusahaan.

Jika awal kolektabilitas kredit bermasalah tidak ditangani dengan tepat maka kolektabilitas kredit akan terus bertambah sehingga kredit diragukan mengalami peningkatan dan sangat berpeluang untuk menjadi kredit macet. Pentingnya penanggulangangan kredit diragukan belum dijalankan secara penuh dan menjadi prioritas bagi pihak bank, kredit diragukan merupakan kolektabilitas kredit tertinggi yang masih diselamatkan, berhubung dengan tanpa adanya penyelesaian kredit diragukan maka pihak bank akan melakukan tahap akhir dalam penanganan kredit bermasalah yaitu lelang jaminan. Oleh sebab itu, untuk mengantisipasi diragukan kemungkinan munculnya kredit diragukan diperlukannya suatu sistem pengendalian internal terhadap penyaluran kredit oleh bank kepada calon debiturnya. Pengendalian internal dalam hal ini merupakan seperangkat ketentuan atau prosedur yang 
akan membantu pihak manajemen untuk mengamankan aktiva perusahan, menguji ketelitian dan keandalan data bank, meningkatkan efisiensi dan ketaatan terhadap kebijakan yang telah digariskan oleh pimpinan bank. Berdasarkan uraian latar belakang diatas, maka rumusan masalah dalam penelitian ini adalah : Apakah Pengendalian Internal Terhadap Kredit Diragukan sudah sesuai dengan konsep pengendalian internal menurut COSO?

Berdasarkan rumusan masalah yang ada, tujuan dilakukannya penelitian ini adalah untuk mengevaluasi apakah pengendalian internal terhadap kredit diragukan sudah sesuai dengan konsep pengendalian internal menurut COSO.

\section{TINJAUAN PUSTAKA}

\subsection{Akuntansi}

Pengertian akuntansi menurut Accounting Principal Board (1970)adalah suatu kegiatan jasa. Fungsinya menyediakan informasi kuantitatif, umumnya dalam ukuran uang mengenai suatu badan ekonomi yang dimaksudkan untuk digunakan dalam pengambilan keputusan ekonomi sebagai dasar memilih diantara beberapa alternatif. (Syafri 2011 : 5). Menurut American Accounting Asssociation (1996)dalam Halim dan Kusufi (2012:36) akuntasni adalah suatu proses pengidentifikasian, pengukuran, pencatatan, dan pelaporan transaksi ekonomi(keuangan) dari suatu organisasi/entitas yang dijadikan informasi dalam rangka pengambilankeputusan ekonomi oleh pihak-plihak yang memerlukan.

\subsection{Akuntansi Manajemen}

Menurut Rudianto (2013) akuntansi manajemen adalah sistem informasi dimana informasi yang dihasilkan ditujukkan kepada pihak-pihak internal organisasi, seperti manajer kauangan, manajer produksi manajer pemasaran, dan sebagainya guna pengambilan keputusan internal perusahaan.

\subsection{Pengendalian Internal}

Menurut Hery (2013:15) "Pengendalian internal adalah seperangkat kebijakan dan prosedur untuk melindungi aset atau kekayaan perusahaan dari segala bentuk tindakan penyalagunaan, menjamin tersedianya informasi akuntansi perusahaan yang akurat, serta memastikan bahwa semua ketentuan (peraturan) hukum/undang-undang serta kebijakan manajemen telah dipatuhi atau dijalankan sebagaimana mestinya."

\subsubsection{Konsep Pengendalian Intern Menurut COSO}

Terdapat lima komponen pengendalian intern menurut COSO (Committee Of Sponsoring Oragnization), yaitu lingkungan pengendalian, penentuan risiko, aktivitas pengendalian, informasi dan komunikasi serta pengawasan atau pemantauan.

a. Lingkungan Pengendalian

b. Penentuan Risiko

c. Akvititas Pengendalian

d. Informasi dan Komunikasi

e. Pengawasan dan Pemantauan

\subsubsection{Tujuan pengendalian internal}

Tujuan pengendalian internal menurut Mulyadi (2013:163), secara garis besar dirumuskan 4 tujuan pengendalian intern yaitu:

a. Menjaga keamanan harta perusahaan

b. Memeriksa ketelitian dan kebenaran akuntansi.

c. Memajukan / mendorong efisiensi dalam operasi.

d. Efisiensi senantiasa berusaha untuk dicapai oleh setiap organisasi. 
e. Mendorong dipatuhinya kebijakan manajemen.

\subsection{Kredit}

Menurut Undang-Undang RI No. 7 tahun 1992 sebagaimana telah diubah dengan undang-undang No. 10 tahun 1998 pasal 1 ayat 11 tentang Perbankan, menyatakan bahwa :"Kredit adalah penyediaan uang atau tagihan yang dapat dipersamakan dengan itu, berdasarkan persetujuan atau kesepakatan pinjam meminjam antara Bank dengan pihak lain yang mewajibkan pihak peminjam untuk melunasi utangnya setelah jangka waktu tertentu dengan pemberian bunga."

\subsubsection{Kredit bermasalah}

Menurut Apriani (2011), Kredit bermasalah (non performing loan) adalah suatu keadaan dimana nasabah sudah tidak sanggup membayar sebagian atau seluruh kewajibannya kepada bank seperti yang telah diperjanjikan.

\subsubsection{Kredit Diragukan}

Sesuai ketentuan Direksi Bank Indonesia No. 31/147/KEP/DIR tanggal 12 November 1998 tentang kualitas aktiva produktif, kredit diragukan didefinisikan:

1. Kredit diragukan berdasarkan prospek usaha

a. Industry atau kegiatan usaha menurun

b. Persaingan usaha sangat ketat dan operasional perusahaan mengalami permasalahan yang serius

c. Manajemen kurang berpengalaman

2. Kredit diragukan berdasarkan kondisi keuangan debitur

a. Laba sangat kecil dan negatif

b. Kerugian operasioanal dibaiayai dengan penjualan aset

c. Rasio utang terhadap modal tinggi

d. Likuiditas sangat rendah

e. Analisis arus kas menunjukkan ketidakmampuan membayar pokok dan bunga

f. Kegiatan usaha terancam karena perubahan nilai tukar valuta asing dan suku bunga

g. Pinjaman baru digunakan untuk memenuhi kebutuhan yang jatuh tempo

3. Kredit diragukan berdasarkan kemampuan membayar

a. Terdapat tunggakan pokok dan/atau bunga yang telah melampaui 180 hari sampai dengan 270 hari

b. Teradi cerukan/overdraft yang bersifat permanen khusunya untuk menutupi kerugian operasional dan kekuarangan arus kas

c. Hubungan debitur dengan bank semakin memburuk dan informasi keuangan debitur tidak tersedia atau tidak dapat dipercaya

d. Dokumentasi kredit kurang lenkap dan pengikat agunan yang lemah

e. Pelanggaran yang principal terhadap persyaratan pokok dan perjanjian kredit

\subsection{Pengendalian Internal Perkreditan}

Harold Koontz dikutip Drs H Malayu SP Hasibuan (1996;245) mengatakan Pengendalian kredit adalah usaha-usaha untuk menjaga agar kredit yang diberikan tetap lancar, produktif dan tidak bermasalah

\subsection{Penelitian Terdahulu}

1. Linda Sari (2014) dalam penelitian yang berjudul Evaluasi pengendalian internal sistem pemberian kredit di Bank DKI Jakarta. Tujuan penelitian ini unltuk mengetahui apakah 
pengendalian internal menunjang proses pe4mberian kredit di Bank DKI. Hasil penelitian menunjukkan Pengendalian internal yang diterapkan di Bank DKI telah sesuai dengan lima (5) komponen COSO (Committee Of Sponsoring Oragnization) dan sangat menunjang dalam prosedur pemberian kredit.

2. Widiasmara (2014) dalam penelitian yang berjudul Analisis pengendalian internal atas piutang untuk meminimalkan piutang usaha tak tertagih tertagih pada PT.OMF. Tujuan penelitian ini adalah unutk mengetahui apakah pengendalian internal sudah berjalan efektif dan efisien serta dapat meminimalkan piutang usaha tak tertagih. Hasil penelitian menunjukkan sistem pengendalian internal atas piutang berpengaruh dalam meminimilasi jumlah piutang tak tertagih.

3. Ellis Kofi Akwa Sekyi (2015) dalam penelitian yang berjudul Effect of internal controls on credit risk among listed Spanish. Tujuan penelitian ini adalah untuk mengetahui peranan pengendalian internal kredit dalam menilai risiko kredit. Hasil penelitian menunjukkan pengendalian internal yang dijlankan perusahaan sudah efektif.

\section{METODE PENELITIAN}

Penelitian yang dilakukan pada PT. Bank SulutGo Kantor Cabang Kawangkoan(Jl. Raya kawangkoan) Bulan Agustus 2017 dan PT. Bank SulutGo KC Tondano Jl. Raya Tountemboan Masarang Bulan September - Oktober 2017 penelitian ini adalah penelitian kualitatif. Menurut Sugiyono (2016:1) menyatakan bahwa metode penelitian kualitatif adalah metode penelitian yang digunakan untuk meneliti pada kondisi objek yang alamiah, dimana peneliti adalah sebagai instrument kunci, teknik pengumpulan data dilakukan secara triangulasi (gabungan), analisis data bersifat induktif, dan hasil penelitian kualitatif lebih menekankan makna dari pada generalisasi.

\subsection{Jenis dan Sumber Data}

Jenis data dalam penelitian ini adalah data kualitatif, data kualitatif yaitu data yang diperoleh dalam bentuk informasi melalui wawancara yang dilakukan terhadap narasumber (responden) yang telah ditentukan sebelumnya. Jenis data kualitatif diperoleh dari sumber primer dan sumber sekunder, seperti: sejarah perusahan, struktur oragnisasi, pembagian tugas, pengendalian internal kredit dan kegiatan perusahan berkaitan dengan prosedur pemberian kredit.

Indrawan et.all (2014:141) menyatakan bahwa sumber data terbagi atas dua bagian yaitu sumber primer dan sumber sekunder sebagai berikut:

1. Data primer adalah data yang diambil langsung dari perusahaan tempat dilakukannya penelitian melalui observasi dan wawancara, dengan terjun langsung ke lapangan dan pengamatan OTS (On The Spot).

2. Data sekunder adalah data yang diperoleh dari hasil dokumentasi baik itu dari studi kepustakaan, buku pedoman dan aturan pemberian kredit, jurnal-jurnal ilmiah dan juga dari internal perusahan yang berkaitan dengan pembagian tugas, struktur oragnisasi serta dokumen-dokumen terkait prosedur pemberian kredit perbankan.

\subsection{Metode pengumpulan Data}

Sugiono (2016:63) menyebutkan dalam penelitian kualitatif pengumpulan data dilakukan pada natural setting (kondisi yang alamiah), sumber data primer, dan teknik pengumpulan data lebih banyak pada observasi berperan (participant observation), wawancara mendalam (in depth interview) dan dokumentasi. Penelitian ini dilakukan dengan mengumpulkan data-data melalui wawancara dan dokumentasi. 


\subsection{Metode Analisis Data}

Teknik analisis data yang digunakan dalam penelitian ini adalah analisis data kualitatif, mengikuti konsep yang diberikan Miles and Huberman. Menurut Miles and Huberman dalam Sugiono (2016:91) yaitu sebagai berikut:

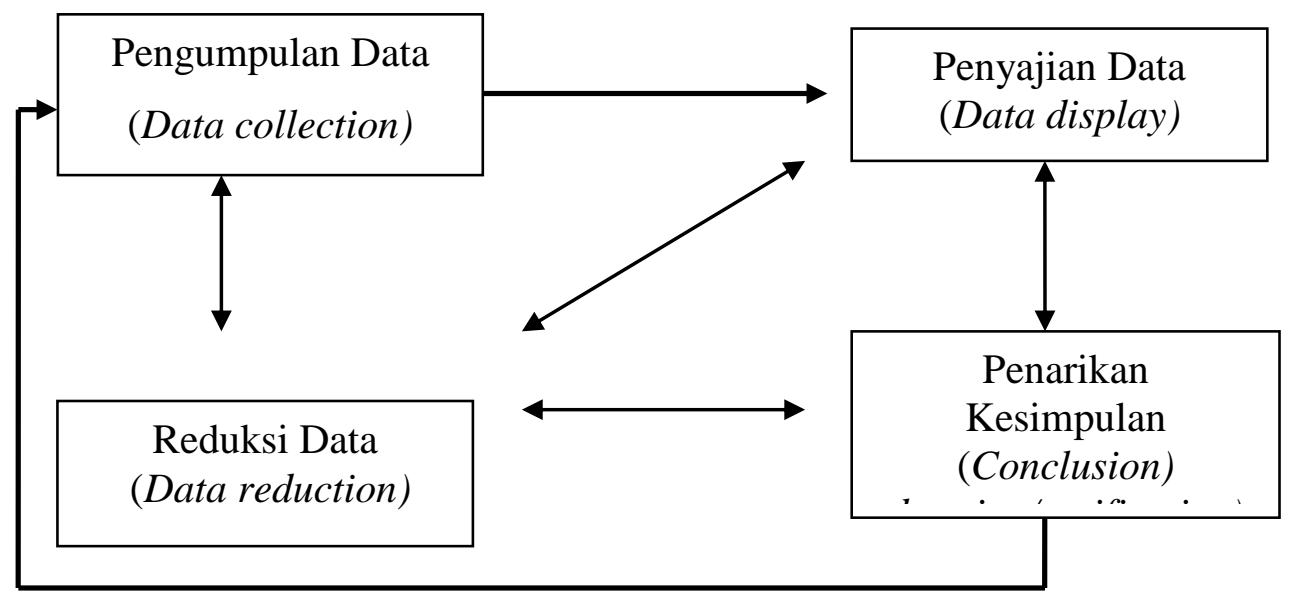

Gambar Alur Analisis Data Model Miles and Huberman

\section{HASIL PENELITIAN DAN PEMBAHASAN}

\subsection{Hasil Penelitian}

\subsubsection{Gambaran Umum Objek Penelitian}

Sebagai perseroan terbatas maka pendirian Bank Sulut dilakukan dengan akta no. 7 tanggal 14 April 1999 dibuat dihadapan JoanesTommy Lasut, SH, notaries di Manado yang disahkan oleh Menteri Kehakiman RI dengan keputusan no. C-8296.HT.01.0x1.TH'99 tanggal 14 Mei 1999 dan telah dimumkan dalam berita Negara R.I. No. 63 tanggal 6 Agustus 1999 dan tambahan berita Negara R.I. No. 4772. Sesuai dengan hasil rapat umum pemegang saham luar biasa PT Bank Sulut tanggal 8 Mei 2015, Keputusan Menteri Hukum dan Hak Asasi manusia RI dengan No. AHU-0935695.AH.01.02 tahun 2015 tanggal 23 Mei 2015 dan keputusan dewan komisaris otoritas jasa keuangan No. 17/KDK.03/2015 tanggal 23 September 2015 maka PT Bank Pembangunan Daerah Sulawesi Utara (PT. Bank Sulut) berubah menjadi PT Bank Pembangunan Daerah Sulawesi Utara Gorontalo (PT Bank SuluGo) 


\subsubsection{Prosedur pemberian kredit di PT. Bank SulutGo Kantor Cabang}

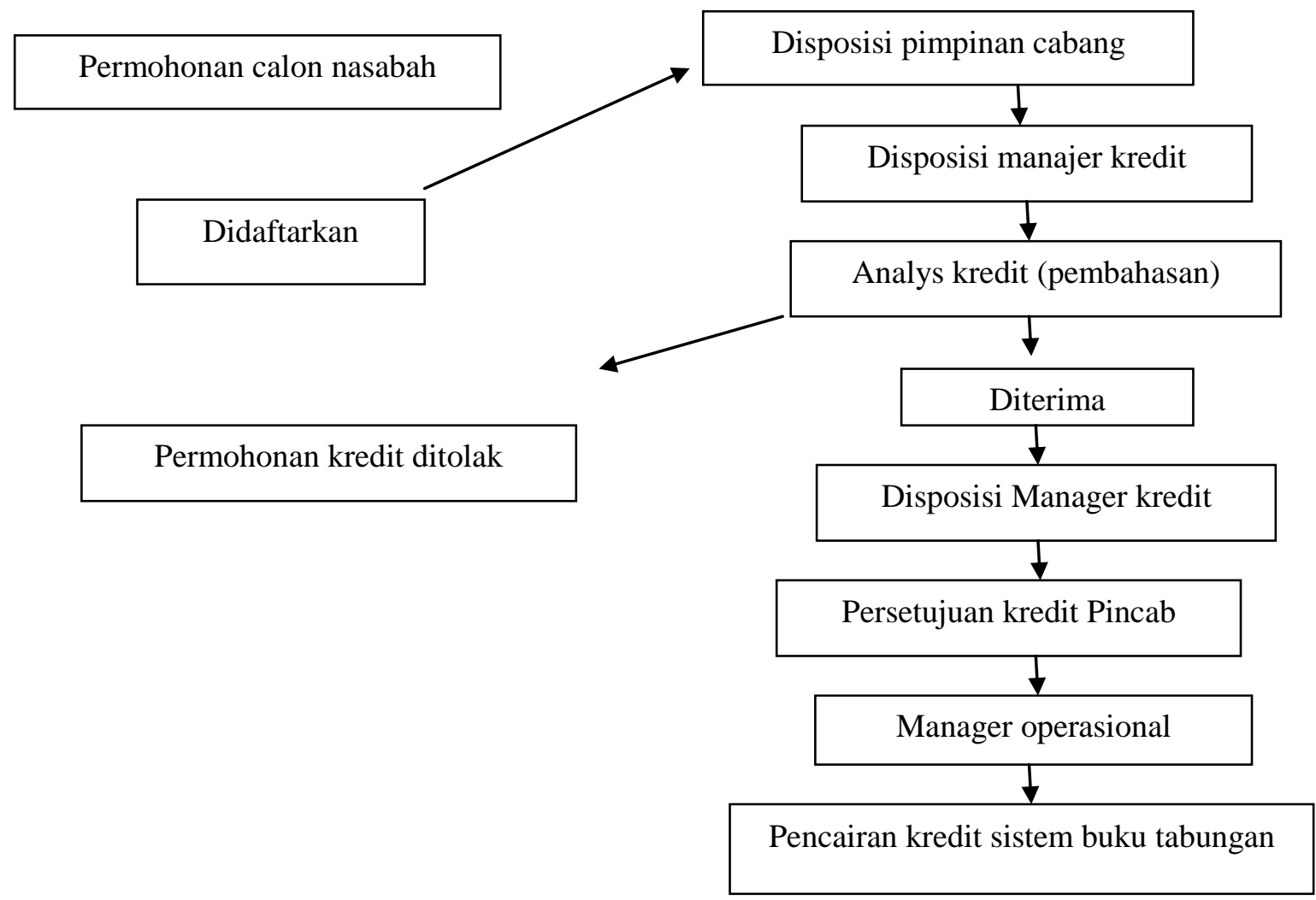

Sumber: PT Bank SulutGo (2017)

\subsubsection{Pengendalian Internal Terhadap Kredit Diragukan pada PT. Bank SulutGo di Minahasa Induk}

\section{Lingkungan Pengendalian}

Manajemen PT. Bank SulutGo di Minahasa menjunjung tinggi integritas, nilai-nilai etika dan kedisiplinan. Setiap bagian/seksi memiliki integritas yang tinggi sehingga dalam proses pengambilan kebijakan semua dibicarakan terlebih dahulu dan mendapat persetujuan dari Pincab (Pimpinan Cabang). Penyebab kredit diragukan salah satunya adalah pelanggaran yang principal terhadap persyaratan pokok dan perjanjian kredit sehingga pihak perusahaan juga terus mengingatkan para karyawan terutama pada bagian kredit untuk tidak menerima imbalan dari nasabah dalam bentuk apapun pada saat menerima data dari calon nasabah, ini adalah bagian dari penanggulangan awal bank terhadap munculnya kredit diragukan. Setiap karyawan mempunyai kompetensi.

Karyawan bagian kredit yang menjalankan fungsinya dengan baik, mulai dari fungsi penerimaan berkas calon nasabah, proses pencairan kredit, dan pemantauan pembayaran angsuran kredit dilakukan dengan baik, sehingga munculnya kredit bermasalah itu sangat minim, juga ketika penyelesaian kredit diragukan dapat ditangani dengan baik sehingga kredit tersebut menjadi lancar kembali, maka pihak bank akan memberikan penghargaan berupa bonus ataupun kenaikan jabatan. Dan ada pihak intern dan pihak ekstern yang mengaudit perusahaan. . Pimpinan cabang sebagai pimpinan pejabat tertinggi dalam kantor cabang yang bertanggung jawab langsung dalam evaluasi kinerja karyawan, memberikan arahan pada karyawan, dan juga yang bertanggung jawab dengan target dan pencapaian, sehingga sebelum melakukan aktivitas pada hari operasional perusahaan melaksanakan breafing yang dipimpin langsung oleh pimpinan cabang hal-hal yang dibahas berkaitan dengan pencapaian, tujuan dan target. 


\section{Penafsiran Risiko}

a. Perubahan dalam lingkungan operasi perusahaan (changes in operating environment)Pencairan kredit dengan menggunakan sistem buku tabungan dan penerapan sistem AKL atau verifikasi transaksi

b. Karyawan Baru.

Perusahaan telah memperketat seleksi calon karyawan dan menetapkan standar kualifikasi pendidikan bagi calon karyawan yang disesuaikan dengan jenis pekerjaan yang ditawarkan. Perusahaan juga memberikan pelatihan-pelatihan bagi karyawan baru, terutama karyawan di bagian kredit.

c. Memperhatikan suku bunga dasar kredit

Tabel 1. Suku Bunga Dasar Kredit

\begin{tabular}{|c|c|c|c|c|c|}
\hline \multirow[b]{3}{*}{$\begin{array}{c}\text { Suku Bunga Dasar } \\
\text { Kredit }\end{array}$} & \multirow{3}{*}{$\begin{array}{c}\text { Kredit } \\
\text { Korporasi } \\
11.63 \%\end{array}$} & \multirow{3}{*}{$\begin{array}{c}\begin{array}{c}\text { Kredit } \\
\text { Ritel }\end{array} \\
11.93 \%\end{array}$} & \multirow{3}{*}{$\begin{array}{l}\text { Kredit } \\
\text { Mikro }\end{array}$} & \multicolumn{2}{|c|}{$\begin{array}{c}(\% / \text { Tahun }) \\
\text { Kredit Konsumsi }\end{array}$} \\
\hline & & & & KPR & Non KPR \\
\hline & & & & $11.63 \%$ & $11.93 \%$ \\
\hline \multicolumn{6}{|c|}{ Sumber Data: $\underline{\text { www.banksulut.co.id }}$} \\
\hline \multicolumn{6}{|c|}{$\begin{array}{l}\text { Credit analysis sebelum keputusan kredit dibuat. } \\
\text { Perangkat analisa untuk melakukan analisa-analisa apakah nasabah tersebut laya } \\
\text { untuk menerima dana kredit dari pihak bank Pada tahap ini kemungkinan adany } \\
\text { kredit diterima atau ditolak. Jika berkas-berkas kredit yang diberikan oleh nasaba } \\
\text { diperiksa dengan teliti dan tidak memihak oleh analis kredit maka sangat keci } \\
\text { kemungkian kredit itu bermasalah. Jika sebaliknya, dokumentasi kredit kuran } \\
\text { lengkap dan pengikat agunan yang lemah, kredit yang diberikan tersebut berpotens } \\
\text { besar menjadi kredit diragukan. }\end{array}$} \\
\hline
\end{tabular}

\section{Aktivitas Pengendalian}

a. Evaluasi kinerja bagian kredit yang dilakukan oleh pimpinan cabang dengan berpedoaman pada goal setting target triwulan pada tahun anggaran tertentu. Serta melaksanakan evaluasi mingguan.

b. Pemisahan fungsi karyawan yang berhubungan dengan kredit menjadi salah satu aktivitas pengendalian untuk kredit diragukan.

c. Kredit diotorisasi oleh pimpinan dan pejabat yang berwenang.

d. Aktivitas pengendalian berkaitan dengan informasi debitur pada saat penilaian kredit dalam bentuk penyusunan memo penilaian kredit, perusahaan melakukan solisitasi dan on the spot.

\section{Informasi dan Komunikasi}

Sistem informasi dan komunikasi yang diterapkan oleh PT. Bank SulutGo di Minahasa Induk telah menggunakan sistem yang terkomputerisasi yaitu:

1. Adanya sistem BI Checking

2. Adanya sistem OLIBS (On Line Integrated Banking System)

\section{Pemantauan}

Pemantauan dilakukan tiap bulan apabila pembayaran sudah jatuh tempo dan debitur belum membayar maka, pihak bank akan menghubungi debitur lewat via telpon/sms tapi jika tidak direspon maka bank akan melakukan pemantauan langsung dengan cara melakukan 
pengecekan dan seksi yang bertanggung jawab; seksi pemasaran. Dan ICRO sebagai unit pengawasan yang bergerak disegala aspek operasional bank, adanya audit ekstern meliputi BI (Bank Indonesia), OJK (Otoritas Jasa Keuangan), dan Kantor Akuntan Publik.

\subsection{Pembahasan}

\section{Lingkungan Pengendalian}

Pengendalian internal yang diterapkan dan dijalankan oleh PT. Bank SulutGo sejauh ini sudah berjalan dengan baik. Manajemen menjunjung tinggi integritas, nilai-nilai etika dan kedisiplinan ditandai dengan adanya sanksi untuk karyawan yang melakukan penyimpangan dan karyawan bagian kredit terus diingatkan untuk tidak menerima imbalan apapun dari nasabah, dengan demikian sangat berperan penting pada munculnya kredit diragukan, ketika karyawan tidak menerima imbalan dalam bentuk apapun maka proses penilaian kredit akan menjadi fair bertanggung jawab. Komitmen organisasi atas kompentensi sudah berjalan baik dimana dalam perekrutan karyawan baru harus melewati seleksi yang cukup ketat dan memenuhi kualifikasi tertentu juga dengan adanya sistem kontrak karyawan. . Perusahaan juga memiliki struktur organisasi yang jelas dan Adanya petugas dari kantor pusat Internal control risk officer (ICRO) menandakan pengendalian internal sudah berjalan baik.

\section{Penilaian Risiko}

Penilaian risiko sangat penting bagi manajemen. Manajemen perusahaan terus berupaya untuk meminimalisir risiko kredit yang akan berpengaruh terhadap kredit diragukan. Suatu sistem pengendalian internal yang efektif mengharuskan bank secara terus-menerus mengidentifikasi dan menilai risiko yang dapat mempengaruhi pencapaian sasaran. Untuk mengatasi kondisi di atas maka penentuan risiko dalam sistem pengendalian internal kredit yang dijalankan dengan memperhatikan suku bunga dasar kredit yang akan dipakaikan kepada debitur. Perusahaan juga telah melakukan berbagai perubahan dalam lingkungan operasi perusahaan, terutama dalam bidang perkreditan, proses pencairan kredit sudah tidak lagi dilakukan dengan cara pencairan secara tunai melainkan dengan sistem buku tabungan dan penerapan sistem $A K L$ / verifikasi transaksi.. Adanya prosedur credit analyisis yang ketat menjelaskan bahwa sistem pengendalian internal telah diupayakan dengan baik oleh bank. Dan untuk KC Tondano terjadi hambatan dan keterlambatan dalam proses penilaian kredit berhubung dengan sangat minimnya karyawan pada bagian analis kredit, hal ini memungkinkan adanya penilaian kredit yang kurang transparan, dan juga membuat pelayanan kepada nasabah kurang maksimal.

\section{Aktivitas Pengendalian}

Aktivitas pengendalian dalam sistem pengendalian atas kredit pada Bank Sulut di Minahasa telah berjalan dengan baik, hal ini dibuktikan dengan prosedur pemberian kredit yang terstruktur mulai dari permohonan sampai dengan pencairan dilakukan dengan pada seksi-seksi yang berbeda, Aktivitas penilaian dan persetujuan kredit dilakukan pada credit analysis kemudian proses evaluasi dan otorisasi dilakukan oleh pimpinan cabang sebagai pejabat tertinggi dalam satu kantor cabang Otorisasi dan strategi dari dari pejabat berwenang dan berkompeten dalam penanganan kredit diragukan merupakan tanggung jawab aktivitas pengendalian pimpinan cabang.. Proses pencairan kredit yang terstruktur, dan ditangani langsung oleh pejabat berwenang, serta otorisasi pimpinan cabang dalam proses pencairan kredit memberi tanda bahwa kredit tersalur dengan prinsip kehati-hatian dengan pertimbangan yang matang berpengaruh terhadap kolektabilitas kredit, dan jika kolektabilitas kredit semakin meningkat maka akan timbulnya kredit diragukan bahkan kemacetan kredit. Perusahaan juga menetapkan Proses kaji ulang kinerja juga diterapkan, dengan cara 
membandingkan laporan keuangan dengan rencana anggaran perusahaan, menandakan aktivitas pengendalian yang sudah memadai.

\section{Informasi dan Komunikasi}

Sistem BI cheking yang diterapkan pihak bank merupakan suatu cara yang dilakukan bank untuk bisa meminimalisir risiko kredit yang mungkin terjadi hal ini berhubungan dengan pencocokan data dari data yang diberikan nasabah dengan data yang tercantum dalam SID (sistem informasi debitur) sehingga memungkinkan pihak bank menilai integritas dan kejujuran dari calon nasabah yang akan diberikan dana kredit, dan kejujuran dari debitur, selain itu adanya sistem OLIBS pada bank membuat akumulasi data tentang kredit dari berbagai jenis kredit yang dilayani oleh bank dapat diakses dengan cepat dan risiko kehilangan berkas ataupun dokumen penting dapat diantisipasi. Dapat dilihat pentingnya informasi dan komunikasi terhadap kredit diragukan, keakuratan data yang diterima pihak bank sangat mempengaruhi kredit diragukan dan keakuran data yang diterima dari nasabah tersebut dapat diketahui lewat sistem BI cheking dan OLIBS. Dengan demikian informasi dan komunikasi berperan penting terhadap kredit diragukan.

\section{Pemantauan}

Pengawasan dan pemantauan yang dilakukan oleh pihak perusahaan memiliki peranan penting terhadap kredit diragukan. Pengawasan yang diterapkan oleh Bank SulutGo di Minahasa terhadap kredit diragukan dinilai sudah terlaksana dengan baik. Hal ini dapat dilihat dari proses pengawasan atas kredit merupakan komitmen bersama pada PT. Bank SulutGo sehingga tindakan pengawasan dilakukan oleh setiap unit organisasi sampai dengan pimpinan cabang, Tindakan pengawasan yang dilakukan oleh satu orang pejabat kantor pusat yang ditempatkan dalam perusahaan yaitu pejabat internal control risk officer (ICRO)sebagai unit pengawasan yang bergerak disegala aspek operasional bank, baik menyangkut manajemen, organisasi maupun prekreditan pengawasan terhadap aktivitas pemberian kredit, aktvitas karyawan yang bertugas dimasing-masing bagian.. Audit ekstern dari BI (Bank Indonesia), OJK (Otoritas Jasa Keuangan), dan Kantor Akuntan Publik. Pengawasan yang ketat yang di terapkan oleh pihak perusahaan baik dari pihak intern dan ekstern dapat meminimalisir kredit diragukan, karena pengawasan yang sesuai dengan prosedur dapat memberi rasa segan bagi para debitur dalam rangka kelancaran pembayaran angsuran.

\section{KESIMPULAN DAN SARAN}

\subsection{Kesimpulan}

Adapun kesimpulan yang diperoleh dengan dilaksanakannya penelitian tentang pengendalian internal atas piutang usaha pada PT. Bank SulutGo di Minahasa Induk bahwa secara keseluruhan pengendalian internal pada PT. Bank SulutGo di Minahasa Induk berjalan cukup baik dan sudah sesuai dengan konsep pengendalian internal menurut COSO, pihak manajemen bank telah menerapkan prinsip-prinsip pengendalian internal menurut COSO. Sistem dan prosedur yang memadai yang dimiliki oleh bank serta ditunjang dengan karyawan-karyawan yang berkompeten membuat tingkat kesalahan yang signifikan atas pengendalian kredit dapat diatasi dengan cepat.

\subsection{Saran}

1. Bagi perusahaan

a. Khusus untuk PT. Bank SulutGo KC Tondano, disarankan untuk menambah karyawan bagian analys kredit yang, berhubung dengan banyaknya nasabah. 
b. Sebaiknya dalam melakukan survey kepada calon debitur lebih memperhatikan kondisi calon debitur apakah memenuhi persyaratan atau tidak berdasarkan prinsip 5C, sebab penilaian awal pada debitur sangat berpengaruh akan prospek kredit ketika sudah diberikan.

c. Perusahaan juga harus dapat mempertahankan sistem pengendalian internal yang telah dilakukan, karena sejauh ini sistem pengendalian internal yang diterapkan perusahaan sudah efektif dan efisien.

2. Bagi pihak lain

a. Perusahaan lain yang menghadapi permasalahan yang hampir sama untuk melakukan perbaikan dan evaluasi sistem pengendalian internal kredit agar lebih efektif.

b. Disarankan bagi peneliti lain yang akan mengadakan penelitian lanjutan dari permasalahan dalam penelitian ini agar lebih kritis dalam membaca kondisi perusahaan dalam penerapan sistem pengendalian atas kredit.

\section{DAFTAR PUSTAKA}

Andi, Paul Saerang, Meily Kalalo. 2017. Analisis sistem pengendalian internal atas piutang usaha pada PT. Bank SulutGo KCP Ranotana. Jurnal EMBA Vol 5 NO 2. Juni 2017. Fakultas ekonomi dan bisnis. Jurusan Akuntansi. Fakultas ekonomi dan bisnis. Universitas Samratulangi. http://ejournal.unsrat.ac.id article/view

Amin Widjaya Tunggal. 2013. Pokok-pokok auditing dan jasa asurans. Jakarta. Harvindo Committee of Sponsoring Organizations of the Treadway Commission (COSO). 2013.

Dewi, Darminto, Endang. 2014. Analisis manajemen kredit guna meminimalkan kredit bermasalah(studi pada bank perkreditan rakyat pancadana batu). JAB. Vol 9 No 2. April 2014. Jurusan Administrasi bisnis. Universitas Brawijaya. http://ojs.unud.ac.id./article/view

Ellis Alfi Akwa, 2014. Effect of internal control on credit risk among listed Spanich Bank. International Journal of Management and Economics Invention. Vol. 1 Issues 04. School Of Business \& Economics. De Lieda University. http://upcommons.upc.edu.handle

Indrawan, Rully dan Yaniawati, Poppy. 2014. Metodologi Penelitian Kuantitatif dan Kualitatif, dan Campuran untuk Manajemen, Pembangunan dan Pendidikan.

Kasmir. 2014. Bank dan lembaga keuangan bank. Edisi Revisi PT. Raja Grafindo Persada. Mulyadi, 2013. Sistem Akuntansi. Jakarta: Salemba Empat

Hery, 2013. Akuntansi Keuangan Menengah. Center of Academic Publishing Service. Yogyakarta.

Purwatiasih, Ayu Dwi dkk. 2014. Analisis Pengendalian Internal Dalam Pemberian Kredit pada PT. BPR Kanaya. e-Journal S1 Ak. Jurusan Akuntansi Program S1. Universitas Pendidikan Ganesha Singaraja. http://ejournal.undiksha.ac.id/index.php/S1ak/article/view/2950/2445

Rudianto. 2013. Akuntansi manajemen informasi untuk pengambilan keputusan strategis. Jakarta. Erlangga.

Sugiono. 2016. Memahami Penelitian Kualitatif. Alfabeta. Bandung.

Widiasmara, Anny. 2014. Analisis Pengendalian Intern Piutang Usaha Untuk Meminimalkan Piutang Tak Tertagih (Bad Debt) pada PT. Wahana Ottomitra Multiartha. Tbk Cabang Madiun. Volume 10 Nomor 2. Juni 2014. http://ejournal.unikama.ac.id/index.php/JEKO/article/view/78 